\title{
INTERPERSONAL BULLYING BEHAVIOURS IN THE WORKPLACE
}

\author{
CHARLOTTE PIETERSEN \\ charlottep@ul.ac.za \\ Department of Business Management \\ University of Limpopo
}

\begin{abstract}
In this paper employing a phenomenological method to explicate seven informants' experience of interpersonal bullying behaviors in a South African work context, I demarcated four general themes namely: lack of recognition, discrimination, obstructionism, and isolation. Moreover, I found that perpetrators (male and female managers) predominantly used verbal and indirect negative acts to bully subordinates. Finally, racial tensions contributed to bullying behavior. While a phenomenological approach shows promise to explore local bullying behavior more research is needed to broaden our understanding of the phenomenon, including explicating bullying through the eyes of bystanders and alleged bullies.
\end{abstract}

Key words

Bullying behaviours, workplace bullying, interpersonal bullying, downwards bullying, phenomenological method

Bullying is an important issue in the contemporary workplace (see Höel, Rayner \& Cooper, 1999; Rayner \& Sheehan, 1999). It appears to be a universal phenomenon and there is a growing recognition that it occurs across organizations and occupations (Cusack, 2000). However, more research is needed to deepen our understanding of the phenomenon in different national and organizational cultures (Höel, 2004). South Africa is one of the countries where awareness of, and research into workplace bullying, is still in its infancy. So far, only a few researchers, for example, Marais-Steinman (1998), and Kirsten, Rossouw and Viljoen (2005), studied bullying in the South Africa work context.

Research into bullying has traditionally been dominated by the survey method (Lewis, M., 2004; Minton \& Minton, 2004). Various authors criticized the use of structured questionnaires and interview schedules to study bullying (Cowie, 1999; Liefooghe \& Olafsson, 1999). Instead, they recommended that the phenomenon be approached from a qualitative perspective. Indeed Del Barrio (1999), and Einarsen and Skogstad (1996) indicated that the use of inductive research could deepen and broaden our understanding of the phenomenon from the common sense perspective of role players in different work and cultural contexts.

In the light of the preceding discussion I decided to use a phenomenological approach, based on the work of, Giorgi (1985), to explicate the meaning and experience of workplace bullying from the viewpoint of a group of informants in a South Africa work context. This approach includes the following steps: Identification of the phenomenon to be researched; selection of informants; eliciting first person descriptions (protocols); protocol analysis; theme identification, and data explication. The individual research protocols obtained provided remarkably rich sources of information. The protocols were analysed and eight situated themes emerged. In this paper I focus on just one of the themes extracted, namely interpersonal bullying behaviours. My purpose here is to answer the following research question: What is the situated structure of interpersonal bullying behaviours in a South African work context?

Interpersonal bullying behaviours

There is currently no general accepted definition of the concept workplace bullying (Smith, Singer, Höel \& Cooper, 2003). Nevertheless, there seems to be general agreement that workplace bullying could be defined as a sub-cluster of aggressive behaviour that manifests itself in interpersonal work relationships between two individuals or between an individual and a group (Barron, 1998; Dodge, 1991; Olweus, 1993; Smith, 1997; Zapf \& Einarsen, 2001). The majority of definitions of workplace bullying also describes bullying in terms of: the intentionality of bullying; the frequency and duration of bullying behaviours; the reactions of the target; an imbalance and misuse of power; lack of support; and inability of the target to defend him or herself (see Clifton \& Serdar, 2000; Ege, 2004; Einarsen, 1999; Knudson-Baas, Ronvik \& Matthiesen, 2004; Lutgen-Sandvik, Tracy \& Alberts, 2004; Lynch \& Moore, 2004; Lyons, Tivey \& Ball 1995; Matthiesen \& Einarsen, 2004; McAvoy \& Murtage, 2003; Olweus, 1999a; Soares, 2004; Vartia, 1996; Walden \& Höel, 2004).

Bullying occurs horizontally between co-workers, and between female and male managers and subordinates (upwards/ downwards bullying) (Branch, Sheenan, Barker \& Ramsay, 2004). Targets of workplace bullying come from all organizational levels and professions (Rayner \& Höel, 1997). Bullying also occurred in non-profit organizations, such as academic institutions (Community Care, 2004; Lewis, D., 2004). Finally Lewis found that although managers were the principle perpetrators of downward bullying, they were in turn, bullied by more senior managers.

A wide array of (more or less subtle) bullying behaviours was also identified (see Björkqvist, Lagerspetz \& Kaukiainen, 1992; Bjorkqvist, Österman, \& Lagerspetz, 1994; Crick \& Grotpeter, 1995; Leymann, 1996; Lynch, 2002; Namie \& Namie, 2000; Olweus, 1991b; Rivers \& Smith, 1994). These manifestations of bullying include overt, direct physically aggressive acts (such as hitting and pushing), and non-physical, covert (verbal and indirect) acts directed systematically at one or more colleagues or subordinates leading to victimisation of the target. Although physical bullying is rarely reported, other manifestations of bullying occur frequently in the workplace (Keashly, 1998; Quine, 1999). For example, the findings of a study by Einarsen and Raknes (1997) showed that only 2.4 per cent of a sample of male Norwegian ship workers reported having been subjected to physical abuse or threats of such abuse (manifestations of bullying behaviours). However, targets of bullying in a wide range of professions and organizations reported that verbal and indirect tactics were commonly employed (Einarsen, Raknes \& Matthiesen, 1994)

According to Bjorqkvist et al. (1992) and Einarsen et al. (1994), bullying is a gradually evolving process. During the early phases victims are typically subjected to very discrete and indirect bullying behaviour that is difficult to pinpoint. Later on more direct aggressive acts appear. In the end both physical and psychological means of violence may be used. It is possible that perpetrators prefer verbal and indirect tactics to physical bullying because such acts are more acceptable in modern society (Crawford, 1999). 
Rayner and Höel (1997) grouped verbal and indirect bullying behaviours together into five categories: Threats to professional status, threats to personal standing, isolation, excessive overwork, and destabilization. Verbal bullying tactics include, for example, offensive remarks, insults, sarcasm and criticism (Alleyne, 2004; Haslam, 2004; Serghis, 1998). Indirect bullying actions include, for example, social isolation, and task related bullying (Björkqvist, et al., 1994; Cusack, 2000; Hood, 2004).

\section{RESEARCH DESIGN}

\section{Research approach}

Felson and Tedeschi (1993), and Liefooghe and MacKenzie Davey (2001) strongly recommend the use of a phenomenological approach to explicate our understanding of bullying behaviours. In this study I wanted to explore the experience of interpersonal bullying behaviours in a South African work workplace. My experience and review of literature, led me to conclude that more research is needed to deepen our understanding of the phenomenon in local contexts. Based on my previous experience I chose to approach the study from a phenomenological-existential perspective. I applied this approach to capture research informants' first order, real life experiences in a specific context (Beshai, 1971; Van Vuuren, 1992), and to curb my own preconceived ideas regarding the phenomenon under investigation.

\section{The phenomenological method}

The purpose of qualitative research is to describe, interpret and understand the meanings to persons of phenomena that occur more or less naturally in interpersonal contexts (Giorgi, 1970). As such it is uniquely appropriate to the study of human experience (Ashworth, 2000). The focus of phenomenology is closely linked to purpose of qualitative research. Phenomenology "focuses on the meanings and significance given to an experience by those who experience it" (Willis, 2004, p. 3). According to Willis such knowledge is of great interest to various social science disciplines.

As an industrial psychologist I am interested in the application of phenomenology in the world of work. According to Cassell and Symon (1994), phenomenological research is appropriate to understand the experiences of both groups and individuals in the work context. The nature and format of my research question is typical of a question asked within the phenomenological-existential perspective that forms the basis of phenomenological psychology. Valle, King and Halling $(1989$, p. 6) defined phenomenological psychology as "...that psychological discipline that seeks to explicate the essence and structure of human experience and behaviour as revealed through essentially descriptive techniques, including disciplined reflection". It is concerned with realityconstituting interpretive practices and examines how human beings experience, construct and give meaning to their subjective experiences in concrete everyday situations (Denzin \& Lincoln, 1994). Phenomenological-existential studies are not driven by preconceived theoretical constructs and research hypotheses, but a desire to explicate a given phenomenon (and reveal the essences appertaining), the researcher can expect to be deeply immersed in data which may seem obtuse. This initial obfuscation can (and should) be met with an attitude of openness and a willingness on the part of the researcher to allow the phenomena to present itself. Rigorous attention to method is important here, and the phenomenological epoché (bracketing out any preconceived ideas and allowing data to speak for itself) has to be employed so that the revealed experiences are uncontaminated by prior learning and bias (Ashworth, 1996; Caelli, 2001; Caelli, 2002; Davey, 1999; Groenwald \& Schurink, 2003; Van der Mescht, 2004)
The use of the phenomenological method linked phenomenology and existentialism in psychology. In phenomenological research method refers to the research technique and the procedure for carrying out the research (Van Manen, 1990; Sadala \& Adorno, 2001). The phenomenological method is employed to locate underlying themes or patterns in a search for underlying structure to describe and understand informants' subjective experiences of a specific phenomenon (Morse, 1994; Royce, 1982), as is the purpose of the present study. It is based on a grounded, inductive approach and based on descriptions of individual experiences in a personal, firstorder language that is as close to the lived experience as possible (Brockelman, 1980; Giorgi, 1970; Kruger, 1988; Laverty, 2003; Polkinghorne, 1982; Schurink, 1988). Research participants are seen as informants or more accurately, active constructors of meaning in the research event. They are required to reflect upon and report their experiences of the research event.

The general format of the phenomenological method may be summarized as follows (Polkinghorne, 1989): gathering a number of naive descriptions from persons who are having or had the experience under investigation; analyzing the descriptions in order to grasp common elements that make the experience what it is; describing or giving a clear, accurate, and authentic account of the phenomenon so that it can be understood by other.

Researchers who used the phenomenological method disagreed on the number of steps to be included (Edwards, S.D., 1991; Moustakas, 1994; Spiegelberg, 1972; Van Kaam, 1969). Stones (1988) recommended that the steps of the phenomenological method should be viewed as a set of guidelines and not as a method per se. This means that a researcher should use his or her discretion when choosing these steps. According to Stones (1986) there are three main variants of the phenomenological method. Spiegelberg (1965), as well as Stones (1998), concentrate on the phenomenological method developed under the leadership of Giorgi. Although the method allows some freedom, Giorgi (1985) described it as a rigorous, systematic, and descriptive method for doing justice to human phenomena as they are lived and experiences.

In this paper I used the phenomenological approach of Du Toit (1991) and Pietersen (2002). This approach is based on the methodological style of the authors mentioned in the previous paragraph. It entails the following steps: identification of the phenomenon; selection of informants; obtaining first person descriptions (protocols); transcribing the descriptions; reading the descriptions; breaking the descriptions down into natural meaning units (nmus); clustering the nmus into themes; and explicating the data. A natural meaning unit or " $\mathrm{nmu}$ " is " ...a statement made by an individual which is self-defining and self-delimitating in the expression of a single, recognizable aspect of the individual's experience..." (Stones, 1988, p. 153).

In order to increase the trustworthiness and verify the findings of the present study, the following sections are presented such a way that other researchers will be able to follow the investigative process. This will enable you, the reader, to reach similar conclusions given the data gathered, the perspective taken, and research situation. The qualitative researcher prefers the term trustworthiness to reliability and validity (Guba \& Lincoln 1982). Trustworthiness includes four aspects: credibility, transferability, dependability, and confirmability. Verification in inductive research refers to the mechanisms used during the research process to incrementally contribute to the rigor of the study (Morse, Barrett, Mayan, Olson \& Spiers 2002). Specific methodological strategies for demonstrating qualitative rigor include, among others, an audit trail, and confirming results with research informants (Guba 1981; Guba \& Lincoln 1982; Lincoln \& Guba 1985). 


\section{Informants}

I applied purposive, snowball sampling in the study since in phenomenological research data-collection interviews usually continued until the informants introduce no new perspectives. Amongst other, Davey (1999) and Groenwald (2004) recommend the use of purposive sampling to enhance the trustworthiness of a phenomenological study. According to Boyd (2001), a maximum of ten informants are generally sufficient to reach data saturation.

English is the official language of choice in the target institution, an academic institution in South Africa and the informants who 'have had experiences relating to the phenomenon to be researched' (Kruger, 1988, p. 150) and were able to communicate in English were included in the sample. This was done to increase the accuracy of the information.

Seven informants were interviewed:

1. Male - 42 years old, black (Head of Department/Senior academic)

2. Female -36 years old, white (Senior academic)

3. Female -24 years old, white (Junior academic)

4. Female -38 years old, white (Junior academic)

5. Female - 40 years old, indian (Middle manager- nonacademic)

6. Male -55 years, white (Junior academic)

7. Female - 54 years old, black (Head of Department/Senior academic)

\section{Procedure}

An e-mail message was posted on the intranet of the target organization. The purpose of the study was explained in broad terms and staff members were invited to share their experiences of the phenomenon under investigation.

Individual interviews were conducted over a threemonth period. Interviews lasted forty minutes to one hour. Each informant signed an Informed Consent Agreement. This agreement included a statement on the confidentiality of the research data obtained. With the consent of the informants, the interviews were audio taped. The question asked was: 'Tell the story of your experience of being bullied in the workplace'.

Data analysis

1. I transcribed and stored interview data electronically. I personally transcribed the protocols to avoid transcription errors.

2. I read and reread each individual protocol to obtain an intuitive, holistic grasp of the description.

3. Nmus, expressed in the informant's own words, were listed and numbered.

4. The nmus were clustered into themes that appeared to be common to all the informants' descriptions. In order to enhance the credibility and dependability of the data informants were asked to comment on the themes extracted.

\section{FINDINGS AND DISCUSSION}

In order to enhance the trustworthiness of inductive research it is important that readers see the processed data or results (Giorgi 1986). In total, the analysis produced 116 nmus reflecting the informants' experiences of bullying behaviors. Repetitive material was discarded, as recommended by Edwards, D.J.A. (1991). The nmus are listed in Table1. This was done to assist you, the reader, to determine whether what is presented is transferable to other situations and groups.
TABLE 1

NMUS

Number Description

Informant 1

1. "I could not stand it any longer. I went back to my old position after a year"

2. "you are reported not to be doing the right things in the office"

3. "but unfortunately you don't get information"

4. "what has been said behind your back"

5. "he did not use the procedures"

6. "he accused me"

7. "I realised, oh, maybe I am offering my services to a person who do not appreciate me"

8. "he never supports you in anything and you have a manager who at the end says 'do your own thing this is not my problem'"

9. "my report was ignored"

10. "I submitted reports and then the he told me he did not get them"

11. "I volunteered to help in the other office, without extra pay, and he ever even thanked me"

12. "he never apologized for anything"

13. "he wanted to push me out to place a comrade in this position" Informant 2

14. "I transferred after a year"

15. "he always treated me rudely"

16. "he told others that he will get me"

17. "he always complained about my work and nothing that I ever did was OK"

18. "he became hysterical"

19. "he threw a file at me"

20. "he said I used unprofessional language but then he used the same word"

21. "he made sexist remarks like 'you women this and you women that"

22. "he never did it before others"

23. "or used the right procedures, so I could never take him on"

24. "he said I am incompetent"

25. "but I was not allowed to attend the training course"

26. "he never told me that I did my work well"

27. "he made snide remarks"

Informant 3

28. "it has been going on for a lot time, about 3 years"

29. "I never got any recognition for good work"

30. "he did not give me a fair chance to prove myself"

31. "nothing I ever did was good enough"

32. "he ignores my input during meetings but listen to the other men"

33. "does not react on my proposals"

34. "never supports me"

35. "jokes about me behind my back"

36. "I will never get promoted as long as he is here"

37. "he just acknowledged my two requests for promotions and nothing happened"

38. "he said a woman should not 'rock the boat"

\section{Informant 4}

39. "he was my boss for one year, then he moved to a different section"

40. "it is nothing specific that you can put your finger on"

41. "everything I do is wrong"

42. "he does not have time for you"

43. "when you knock on his door or when you are in his office he ignores you"

44. "I stood in his office for 10 minutes and he never looked up"

45. "he turned around and said 'can you not see that I am busy' and I had to leave"

46. "when I try to ignore him in turn he said "how can we get anything done if we do not work together'" 
47. "you are not allowed to become involved in any projects outside of the department"

48. "he goes into a frenzy"

49. "he keeps all the office supplies in his office"

50. "he has the only printer and when I ask him to print something for my classes I have to wait for three weeks and then it is to late"

51. "when I submit a request for paper he ignores it"

52. "I cannot do my work because my equipment is out of order and he ignores requests to do something about it "

53. "he insulted me behind my back in the tearoom"

54. "told by via e-mail that I have to take over a course a week before the start of the course"

55. "I get so overloaded"

56. "unreasonable. I am not qualified to teach third years"

57. "two days before an exhibition was to take place he told me that I had to do it"

58. "accused me of not doing my duty"

59. "he used bad language in a letter to me"

60. "he wrote that he was disappointed in me"

61 "blamed me even though I only followed his instructions"

62. "said I ordered rubbish even though he told me to purchase a specific type of printer for the department"

63. "He never recognized my important involvement in the international project"

64. "I had to use my own money to buy a camera and was never refunded"

65. "he despises women, discriminates against me and only talks to my male colleagues"

66. "he told me that a white Afrikaans speaking person cannot teach here. Our English is not good enough"

\section{Informant 5}

67. "thank God she left after 18 months"

68. "not something specific"

69. "she is noxious"

70. "say one thing and do another"

71. "always keeps you in the dark"

72. "I never know what is going to happen next"

73. "you get absolutely no recognition from the top"

74. "I write proposal and she presents them as her own"

75. "changes things in my unit without consulting me"

76. "keeps on piling on more work"

77. "makes promises that she does not keep"

78. "do not come back to you"

79. "after I took up the position I was told that I cannot get promoted to professor in this job"

80. "She is demonic, she is evil. You think she is the most wonderful person in creation when you first meet her and then you change your mind very quickly. She is very under the ground"

81. "She is setting people against each other all the time"

82. "go behind your back"

83. "and set up obstacles and make as difficult as possible for you to do your work"

84. "You are excited about something and the boss just shoots it down, just like that"

85. "always excuses for not looking at your correspondence to her"

86. "different rules apply to different people"

\section{Informant 6}

87. "he is now gone. It went on for 9 months"

88. "I was unfairly accused"

89. "He blamed me for something I did not do"

90. "He instigated unfair disciplinary actions against me"

91. "He made unfair statements about me behind my back"

92. "it is a racial thing. He does not like white people"

93. "I never know what is going to happen next"

94. "ignored any evidence to the contrary and believed what he wanted to believe"

95. "kept problem private and did not want to discuss it openly at faculty meetings"

96. "He never gave any indication that he saw me as a good lecturer even though my students evaluated me very highly"
Informant 7

97. "She has been in the position for three years"

98. "She writes memos all the time. I do not have the time to respond to them all"

99. "She gets so emotional it is impossible to talk to her. I just sit and listen to her ravings"

100. "I feel 'Please just tell me I am doing something right!"

101. "She stopped me from attending conferences, but then she attends them herself even though they are not in her subject area"

102. "a junior woman was nominated to go to HERS-Academy . I have begged for the past three years to go"

103. "My courses do not get approved. The documents just gather dust on her desk"

104. "She takes my post-graduated students away from me and appoint her own cronies as supervisors after I've worked with the students to get their proposals through the system. It is really unfair. Supervision takes a lot of time and effort and mine is wasted"

105. "She blocked my promotion. As long as she is there I will not get promoted"

106. "She does not greet me in the lift"

107. "I get the impression that she has to force herself to speak to me. She is uncomfortable with a powerful black women"

108. "tries to stop me from asking questions at meetings"

109. "complains about my work all the time and write letters about me to senior management"

110. "keeps my requests on her desk and does not attend to them"

111. "gives stupid excuses"

112. "nitpick over all my correspondence"

113. "she blocks all my reports"

114. "instigated disciplinary action against me. My name was cleared"

115. "creates the impression with others that I am a troublemaker"

116. "tells me there is no money in the budget for student transport, but it is not true"

The findings demonstrate that all the informants experienced downward bullying perpetrated by both male and female managers. All the perpetrators used verbal (37 nmus) and/or indirect (84 nums) tactics to bully their targets.

Examples of verbal bullying: '...he made snide remarks'/'when I try to ignore him in turn he said 'how can we get anything done if we do not work together" $/$ ' ... he used bad language in a letter to me'/'She gets so emotional it is impossible to talk to her. I just sit and listen to her ravings'.

Examples of indirect bullying: '...he did not give me a fair chance to prove myself'/'I stood in his office for 10 minutes and he never looked up'/'She is demonic, she is evil. You think she is the most wonderful person in creation when you first meet her and then you change your mind very quickly. She is very under the ground'.

Only Informant 2 experienced a single overt negative act ('...he threw a file at me'). Although all the bullying incidents took place over a relatively long period of time (from 9 months to 3 years - nums: $1,13,26,38,66,86,96)$ this seemed to indicate that bullying is not always a process as explained by Bjorqkvist et al. (1992) and Einarsen et al. (1994). However, the findings supported Crawford's (1999) idea that people tend to use subtle, 'civilized' bullying tactics rather than more 'primitive', direct forms of violence.

\section{Themes}

Epoché (bracketing) was employed throughout the research process to ensure that the revealed experiences were uncontaminated by my own presupposition or theoretical concepts, and to allow the phenomenon to speak for itself. I also conducted an audit to increase the confirmability of the study (The raw data, data reduction, themes, and process notes were reviewed).

The nums clustered into four themes. In table 2 selected nums, associated with each theme, are provided. 
TABLE 2

\section{NMUS ASSOCIATED WITH THEMES IDENTIFIED}

\begin{tabular}{|c|c|c|}
\hline \multicolumn{2}{|c|}{ Themes } & \multirow{2}{*}{$\begin{array}{l}\text { Themes } \\
\begin{array}{l}7,8,11,17,26,29,31,32,34,41,63,73, \\
74,84,94,96,100,106 .\end{array}\end{array}$} \\
\hline 1. & Lack of recognition & \\
\hline 2. & Discrimination & $13,21,32,38,65,66,86,92,104,107$ \\
\hline 3. & Obstructionism & $\begin{array}{l}1,2,3,8,9,10,25,30,33,35,36,37 \\
42,47,49,50,51,52,54,55,56,57,75 \\
76,77,78,79,83,85,94,98,101,102 \\
103,105,110,111,112,113,116\end{array}$ \\
\hline 4. & Isolation & $\begin{array}{l}4,5,6,12,16,22,23,27,35,53,58,71 \\
72,81,82,88,89,90,91,95,108,114 \\
115 .\end{array}$ \\
\hline
\end{tabular}

The four themes extracted are:

\section{Lack of recognition}

Recognition refers to a show of appreciation or approval. Recognizing contributions made by subordinates is important to maintain their self-esteem and to motivate them. None of the informants received any verbal of indirect recognition from the perpetrators.

Examples: 'I volunteered to help in the other office, without extra pay, and he ever even thanked me'/'I write proposal and she presents them as her own'/'He never gave any indication that he saw me as a good lecturer even though my students evaluated me very highly'.

\section{Discrimination}

Discrimination can take many forms and can have serious consequences in a multi-cultural/multiracial institution. In the present study informants experienced discrimination based on racial and gender prejudice, and favouritism. Both black and white male and female managers were guilty of discrimination. For example,black managers bullied their white female (Informants 2 and 4) and male (Informant 6) subordinates White on white, and back on black bullying were also experienced (Informants 3 and 1). Lastly, white and black managers favoured subordinates from their own cultural backgrounds (Informants 5,6 and 7).

Examples: '...he ignores my input during meetings but listen to the other men'/'...he wanted to push me out to place a comrade in this position'/ '...get the impression that she has to force herself to speak to me. She is uncomfortable with a powerful black women'/ 'He does not like white people'/'...different rules apply to different people'.

\section{Obstructionism}

Obstructionism refers to efforts to block advancement or to interrupt proper functioning. It is characterized by a lack of support and patronage. Perpetrators in the present study bullied their targets by employing obstructive behaviours to impede their career advancement, professional development and effective work functioning. Informants described how perpetrators blocked their career advancement (Informants 1, 3, 7), prevented access to training (Informant 2) and personal develo-pment opportunities, such as conference attendance (Informant 6) and involvement in projects outside of teaching (Informant 4). Informants also described how perpetrators hampered their task performance by withholding resources, information and feedback, setting impossible deadlines and targets, disrupting their normal workflow, and not supporting them.

Examples: '...but I was not allowed to attend the training course'/ 'She stopped me from attending conferences, but then she attends them herself even though they are not in her subject area'/...he just acknowledged my two requests for promotions and nothing happened'/'...you are not allowed to become involved in any projects outside of the department'/'...but unfortunately you don't get information' $/$ '... do not come back to you' $/$ '...he has the only printer and when I ask him to print something for my classes I have to wait for three weeks and then it is to late'/ '...two days before an exhibition was to take place he told me that I had to do it'/'She writes memos all the time. I do not have the time to respond to them all'/'...he never supports you in anything and you have a manager who at the end says 'do your own thing this is not my problem'.

\section{Isolation}

Perpetrators use covert tactics to threaten a target's personal and professional status. One way to do this is to set a target apart from others. The informants' experiences showed that perpetrators attempted to isolate them by engaging in a number of negative acts.

Examples: '...he accused me...'/'...he never did it before others' $/$ '...or used the right procedures, so I could never take him on' $/$ '...jokes about me behind my back' $/^{\prime}$....always keeps you in the dark'/'She is setting people against each other all the time'/'He instigated unfair disciplinary actions against $\mathrm{me}^{\prime} /$ '....kept problem private and did not want to discuss it openly at faculty meetings'/'...creates the impression with others that I am a troublemaker'.

\section{CONCLUSIONS AND RECOMMENDATIONS}

In the literature review interpersonal bullying was identified as a problem in academic institutions. The findings of this study identified it an issue than needs to be attended to in the target institution. Research findings in western countries also showed that downwards bullying by managers is the most common form of bullying in the workplace and that non-physical, covert (verbal and indirect) negative acts are the most common manifestation of interpersonal bullying in the work context. This findings of this study showed that the above were also evident in a South African academic institution. Firstly, most incidents of interpersonal bullying occurred between a superior and a subordinate (irrespective of their rank). Secondly, the majority of negative acts experienced were indirect and verbal in nature. Lastly, bullying behaviours were, for the most part, not gender specific. It is possible that these elements of workplace bullying could be a universal phenomenon.

However, race played a role in bullying in the target organization. This is not surprising in the light of the historical legacy of Apartheid in South Africa. Management should take note of the presence of racial tensions in the institution and intervention strategies should be implemented to deal with this problem.

This study demonstrates the importance of using an inductive approach to study interpersonal bullying. Instead of using pre-determined categories, such as those identified by Rayner and Höel (1997), the use of the phenomenological method allowed me to obtain informants' own conceptions of what comprises interpersonal bullying in the workplace. In the literature a large number of bullying behaviours have been identified (see Hood 2004, Lynch 2002; Namie \& Namie 2000; Rayner \& Sheehan 1999). In the present study the general structure of interpersonal bullying includes the following four elements: lack of recognition, discrimination, obstructionism, and isolation. A novel contribution of this study is that common bullying tactics were grouped into four themes. 
However, the essence of any experience is never totally exhausted. It can only reflect a particular time, place, and the experiences of the individuals interviewed (Moerer-Urdahl $\&$ Creswell, 2004). Therefore, more in-depth qualitative research is needed in South African work contexts to broaden our understanding of interpersonal bullying experienced not only by targets, but also by bystanders in the situation. Bullying behaviours should also be explicated from the perspective of the alleged bully. This will allow a researcher to determine if perpetrators could justify the behaviours experienced by the targets, and to highlight the reasons why perpetrators engage in these types of negative acts. Hopefully my research would stimulate other researchers in South Africa who share my concerns to used qualitative research methods to broaden our understanding of workplace bullying and help organizations and individuals to manage the problem

\section{REFERENCES}

Alleyne, A. (2004). Black identity and workplace oppression. Counselling and Psychotherapy Research Journal, 4 (1), 4-8.

Ashworth, P.D. (1996). Presuppose nothing! The suspension of assumptions in phenomenological psychology methodology. Journal of Phenomenological Research, 27, 1-25.

Ashworth, P.D. (2000). Qualitative research methods. Estudios Pedagógicos, 26, 91-106.

Barron, O. (1998). Bullying at work: The distinction between workplace bullying and workplace violence and the ramification for OHS. Journal of Occupational Health and Safety, Australia and New Zealand, 14 (6), 575-580.

Beshai, J.A. (1971). Psychology's dilemma: To explain or to understand. Journal of Phenomenological Psychology, 1, 209223.

Björkqvist, K., Lagerspetz, K.M.J. \& Kaukiainen, A. (1992). Do girls manipulate and boys fight? Developmental trends in regard to direct and indirect aggression. Aggressive Behaviour, $18,117-127$

Björkqvist, K., Österman, K. \& Lagerspetz, K.M.J. (1994). Sex differences in covert aggression among adults. Aggressive Behaviour, 20, 27-33

Boyd, C.O. (2001). Phenomenology the method. In Munhall, P.L. (Ed). Nursing research: A qualitative perspective. (pp. 93-122). Sudbury, MA: Jones and Bartlett.

Branch, S., Sheenan, M., Barker, M. \& Ramsay, S. (2004). Perceptions of upwards bullying: An interview study. Paper presented at the $4^{\text {th }}$ International Conference on Bullying and Harassment in the Workplace, 28-29 June, Bergen, Norway.

Brockelman, P.T. (1980). Phenomenology and the World of Ordinary Experience: An Introduction. Lanham: University Press of America.

Caelli, K. (2000). The changing face of phenomenological research: Traditional and American phenomenology in nursing. Qualitative Health Research, 10, 366-377.

Caelli, K. (2001). Engaging with phenomenology: It is more of a challenge than it needs to be? Qualitative Health Research, 11 (2), 273-282.

Clifton, J. \& Serdar, H. (2000). Bully off: Recognising and tackling workplace bullying. Lyme Regis: Russell House Publishing.

Community Care. (2004). Even Personnel Staff have been Victims of Bullying at Work. Community Care, 154 (2), 54.

Cowie, H. (1999). Adult bullying. Report of a Working Party chaired by Helen Cowie. University of Surrey, Reohampton (USR).

Crawford, N. (1999). Conundrums and confusion in organisations: The ethmology of the word "bully". International Journal of Manpower, 20 (1/2), 82-107.

Crick, N.R. \& Grotpeter, J.K. (1995). Relational aggression, gender, and social-psychological adjustment. Child Development, 66, 710-722.
Cusack, S. (2000). Workplace bullying: Icebergs in sight, soundings needed. Lancet, 356 (9248), 2118.

Davey, R.J. (1999). Rigorous sex research: A phenomenological perspective. Paper presented at the 1st Association for Qualitative Research, International Conference, 8-10 July, Melbourne, Victoria, Australia.

Del Barrio, C. (1999). The use of semistructured interviews and qualitative methods for the study of peer bullying. Report of the Working Party chaired by Cristina del Barrio, Universidad Autónoma de Madrid, Spain.

Denzin, N.K. \& Lincoln, Y.S. (1994). Introduction: entering the field of qualitative research. In N.K. Denzin \& Y.S Lincoln (Eds.). Handbook of qualitative research. London: Sage.

Dodge, K.A. (1991). The structure and function of reactive and proactive aggression. D.J. \& KH Rubin, K.H. (Eds). The development and treatment of childhood aggression. (pp. 201216). Hillsdale, NJ: Erlbaum.

$\mathrm{Du}$ Toit, M.K. (1991). A phenomenological explication of the human midlife experience. Doctoral Dissertation, University of Zululand, Kwadlangezwa, South Africa.

Edwards, D.J.A. (1991). Duquesne phenomenological research method as a special class of case study research method. In Van Vuuren, R. Dialogue beyond polemics. Pretoria: HSRC.

Edwards, S.D. (1991). Psychology as An agogic science: A tertiary educational investigation. Doctoral Dissertation, University of South Africa, Pretoria, South Africa.

Ege, H. (2004). Assessing workplace bullying for the juridical claim of damages: An empirical method of acknowledgement. Paper presented at the $4^{\text {th }}$ International Conference on Bullying and Harassment in the Workplace, 28-29 June, Bergen, Norway.

Einarsen, S. (1999). The nature and causes of bullying at work. International Journal of Manpower, 20 (1-2),16-28.

Einarsen, S. \& Raknes, B.I. (1997). Harassment in the workplace and the victimization of men. Violence and Victims, 12 (3), 247-63.

Einarsen, S., Raknes, B.I. \& Matthiesen, S.B. (1994). Bullying and harassment at work and their relationships to work environment quality: an exploratory study. European Work and Organisational Psychologist, 4 (4), 381-401.

Einarssen, S. \& Skogstad, A. (1996). Bullying at work: epidemiological findings in public and private organisations. European Journal of Work and Organisational Psychology, 5, 185-201.

Felson, R.B. \& Tedeschi, J.T. (1993). Aggression and Violence: Social Interactionist Perspectives. Washington: American Psychological Association.

Giorgi, A. (1970). Psychology as a Human Science, New York, Harper and Row.

Giorgi, A. (1985). Phenomenology and psychological research. Pittsburg: Duquesne University.

Giorgi, A. (1986). A phenomenological analysis of descriptions of conceptions of learning obtained from a phenomenographic perspective. Department of Education, Göteborg University.

Groenewald, T. (2004). A phenomenological research design illustrated. International Journal of Qualitative Methods, 3 (1) $1-26$.

Groenwald, T \& Schurink, W. (2003). The contribution of cooperative education in the growing of talent in South Africa: A qualitative phenomenological exploration. South African Journal of Human Resource Management, 1 (3), 93-104.

Guba, E.G. (1981). Criteria for assessing the trustworthiness of naturalistic inquiries. Educational Communication and Technology Journal, 29 (2), 75-91.

Guba, E.G. \& Lincoln, Y.S. (1982). Epistemological and methodological bases of naturalistic inquiry, Educational Communication and Technology Journal, 30 (4), 233-252.

Haslam, I. (2004). Welcome to hell's office. Community Care, $1538,49$. 
Höel, H. (2004). Violence and harassment in European workplaces: Trends and political responses. Keynote address presented at the $4^{\text {th }}$ International Conference on Bullying and Harassment in the Workplace, 28-29 June, Bergen, Norway.

Höel, H., Rayner, C. \& Cooper, C.L. (1999). Workplace bullying. International Review of Industrial and Organizational Psychology, 14, 195-230.

Hood, S. (2004). Workplace bullying. Canadian Business, 77 (18), 87-90.

Keashly, L. (1998). Emotional abuse in the workplace: conceptual and empirical issues. Journal of Emotional Abuse, 1 (1), 85117.

Kirsten, G.J.C., Rossouw, J.P. \& Viljoen, C.T. (2005). Bullying by educational managers with narcissistic personality disorder a health protection and psycho-legal issue? Paper presented at the $11^{\text {th }}$ South African Psychology Congress, 21-23 September, Cape Town, South Africa.

Knudsen-Baas, G., Ronvik, T. \& Matthiesen, S.B. (2004). Salutogenesis and shattered assumptions among targets of bullying at work: A case study approach. Poster presented at the $4^{\text {th }}$ International Conference on Bullying and Harassment in the Workplace, 28-29 June, Bergen, Norway.

Kruger, D. (1988). An introduction to phenomenological psychology. (2nd Ed). Cape Town: Juta.

Laverty, S.M. (2003). Hermeneutic phenomenology and phenomenology: a comparison of historical and methodological considerations. International Journal of Qualitative Methods, 2 (3). Retrieved February 13, 2005, from the World Wide Web: http://www.ualberta.ca/ ijqm/ backissues/2 3final/html/laverty.html

Lewis, D. (2004). Workplace bullying and ethnicity: Differences and similarities. Paper presented at the $4^{\text {th }}$ International Conference on Bullying and Harassment in the Workplace, 28-29 June, Bergen, Norway.

Lewis, M. (2004). Will the real bully please stand up. Occupational Health, 56 (5), 22-26.

Leymann, H. (1996). The content and development of mobbing at work. European Journal of Work and Organizational Psychology, 5, 165-184.

Liefooghe, P.D. \& Mackenzie Davey, K. (2001). Accounts of workplace bullying: The role of the organization. European Journal of Work and Organizational Psychology, 10 (4), 375-392.

Liefooghe, P.D. \& Olafsson, R. (1999). "Scientists" and "amateurs": Mapping the bullying domain. International Journal of Manpower, 20 (1/2), 39-48.

Lincoln, Y.S. \& Guba, E.G. (1985). Naturalistic Inquiry. Beverly Hills, CA: Sage.

Lutgen-Sandvik, P., Tracy, S.J. \& Alberts, J.K. (2004). Workplace bullying in the United States: Incidence, comparison to international research and an introduction of bullying 'degree'. Paper presented at the $4^{\text {th }}$ International Conference on Bullying and Harassment in the Workplace, 28-29 June, Bergen, Norway.

Lynch, J. (2002). Workplace bullying: Implications for police organizations. Australasian Centre for Policing, Marden, South Australia.

Lynch, J. \& Moore, M. (2004). Workplace bullying: Psychological effects, coping strategies and personality constructs of recipients of bullying behaviours. Paper presented at the $4^{\text {th }}$ International Conference on Bullying and Harassment in the Workplace, 28-29 June, Bergen, Norway.

Lyons, R., Tivey, H. \& Ball, C. (1995). Bullying at work: How to tackle it. A Guide for MSF Representatives and Members, London: MSF.

Marais-Steinman, M. (1998). The changing workplace: Work trauma and the workplace. Kagiso Publishers: New York.

Matthiesen, S.B. \& Einarsen, S. (2004). About perpetrators and targets of bullying at work. Some personality differences. Paper presented at the $4^{\text {th }}$ International Conference on Bullying and Harassment in the Workplace, 28-29 June, Bergen, Norway.
McAvoy, B.R. \& Murtage, J. (2003). Workplace bullying. British Medical Journal, 326 (7393), 776-777.

Minton, S.J. \& Minton, P. (2004). The application of certain phenomenological/existential perspectives in understanding the bully-victim cycle. Existential Analysis, 15 (2), $1-14$.

Moerer-Urdahl, T. \& Creswell, J. (2004). Using transcendental phenomenology to explore the 'Ripple Effect' in a leadership mentoring program. International Journal of Qualitative Methods, 3 (2), retrieved February 23, 2005, from the World Wide Web: http://www.ualberta.ca/ ijqm/english/ engframeset.html

Morse, J.M. (1994). Designing funded qualitative research. . In N.K. Denzin \& Y.S. Lincoln (Eds.). Handbook of qualitative research. London: Sage.

Morse, J.M., Barrett, M., Mayan, M., Olson, K. \& Spiers, J. (2002). Verification strategies for establishing reliability and validity in qualitative research. International Journal of Qualitative methods, 1 (2). Retrieved February 12, 2005, from the World Wide Web: http://www.ualberta.ca/ ijqm/ english/engframeset.html

Moustakas, C. (1994). Phenomenological research methods. Sage: Thousand Oaks, CA.

Namie, G. \& Namie, R. (2000). Workplace bullying: The silent epidemic. Employee Rights Quarterly, 1 (2), 1-12.

Olweus, D. (1993). Bullying in school: What we know and what we can do. Blackwell : Oxford.

Olweus, D. (1999a). Sweden. In Smith, P.K., Morita, Y., JungerTas, J., Olweus, D., Catalano, R. \& Slee, P., (Eds). The nature of school bullying: A cross-national perspective. (pp. 2-27). London: Routledge.

Olweus, D. (1991b). Bully/victim problems among schoolchildren. In Rubin, I. \& Pepler, D. (Eds), The development and treatment of childhood aggression. (pp. 411447). Hillsdale, NJ: Erlbaum.

Pietersen, C. (2002). Research as a learning experience: A phenomenological explication. The Qualitative Report, 7 (2), retrieved February 13, 2005, from the World Wide Web: http://www.nova.edu/ssss/QR/QR7-2/pietersen.html

Polkinghorne, D.E. (1982). What makes research humanistic? Journal of Humanistic Psychology, 22 (3), 47-54.

Polkinghorne, D.E. (1989). Phenomenological research methods. In R.S. Valle \& S. Halling (Eds.). Existential-phenomenological perspectives in psychology: Exploring the breadth of human experience. New York: Plenum.

Quine, L. (1999). Workplace bullying in NHS Community Trust: Staff questionnaire survey. British Medical Journal, 318 (7178), 228-232.

Rayner, C. \& Höel, H. (1997). A summary review of literature relating to workplace bullying. Journal of Community Applied Social Psychology, 7, 181-191.

Rayner, C. \& Sheehan, M. (1999). Theoretical approaches to the study of bullying at work. International Journal of Manpower, $20(1 / 2), 11-15$

Rivers, I. \& Smith, P.K. (1994). Types of bullying behaviour and their correlates. Aggressive Behaviour, 20, 335-368.

Royce, J. (1982). Philosophical issues, Division 42, and the future. American Psychologist, 43 (9), 683-693.

Sadala, M.L.A. \& Adorno, R. deC. F. (2001). Phenomenology as a method to investigate the experiences lived: A perspective from Husserl and Merleau-Ponty's though. Journal of Advanced Nursing, 37 (3), 282-293.

Schurink, E. (1988). The Methodology of Unstructured Interviewing. In M. Ferreira, J. Mouton, G. Puth, \& E. Schurink. Introduction to Qualitative Methodology: Module 3, HSRC, Pretoria, South Africa, 136-159.

Serghis, D. (1998). Study depicts widespread workplace bullying. Australian Nursing Journal, 5 (10), 1-9.

Smith, P.K. (1997). Bullying in life-span perspective: What can studies of school bullying and workplace bullying learn from each other? Journal of Community and Applied Social Psychology, 7, 249-255. 
Smith, P.K., Singer, M., Höel, H. \& Cooper, C.L. (2003). Victimization in the school and the workplace: Are there any links? British Journal of Psychology, 94 (2), 175.

Soares, A. (2004). Bullying, post-traumatic stress disorders, and social support. Paper presented at the $4^{\text {th }}$ International Conference on Bullying and Harassment in the Workplace, 28-29 June, Bergen, Norway.

Spiegelberg, H. (1972). Phenomenology in psychology and psychiatry: A historical introduction. Northwestern University Press: Evanston.

Spiegelberg, H. (1965). The phenomenological movement: A historic perspective. Volume 2. The Hague: Martinus Nijhoff.

Stones, C.R. (1988). Research: Toward a phenomenological praxis. In Kruger, D. (Ed). An introduction to phenomenological psychology (2nd ed) (141-156). Cape Town: Juta.

Stones, C. R. (1986). Phenomenological praxis: A constructive alternative in research in psychology. South African Journal of Psychology, 16 (4), 117-121.

Van Manen, M. (1990). Researching lived experience. London, Ontaria: State University of New York Press.

Valle, R.S., King, M. \& Halling, S (1989). An introduction to existential-phenomenological thought in psychology. In R.S. Valle \& S. Halling (Eds.). Existential-phenomenological perspectives in psychology: Exploring the breadth of human experience. New York: Plenum.

Van der Mescht, H (2004). Phenomenology in education: A case study in educational leadership. Indo-Pacific Journal of Phenomenology, 4 (1), 1-16.

Van Kaam, A. (1969). Existential foundations of psychology. New York: Images Books.

Van Vuuren, R.J. (1992). Kwalitatiewe navorsing: 'n Werkswinkel oor kwalitatiewe navorsing. 22-25 July. University of the Free State, Bloemfontein, South Africa.

Vartia, M. (1996). The sources of bullying: Psychological work environment and organisational climate. European Journal of Work and Organizational Psychology, 5 (20), 3-14.

Walden, R.M. \& Höel, H. (2004). A preliminary analysis of how bullying and harassment issues are filtered through the constructs of UK law. Paper presented at the $4^{\text {th }}$ International Conference on Bullying and Harassment in the Workplace, 28-29 June, Bergen, Norway.

Willis, P. (2004). From "The things themselves" to a "Feeling of understanding": Finding different voices in phenomeno-logical research. Indo-Pacific Journal of Phenomenology, 4 (1), 1-13.

Zapf, D. \& Einarsen, S. (2001). Bullying in the workplace: recent trends in research and practice-an introduction. European Journal of Work and Organizational Psychology, 10 (4), 369-373. 